\section{YO, INTELECTUAL: PÍO BAROJA FRENTE A LAS MASAS Y LA DEMOCRACIA}

\author{
Francisco Fuster García \\ Departamento de Historia Contemporánea \\ Facultad de Geografía e Historia \\ Universidad de Valencia \\ Francisco.Fuster-Garcia@uv.es
}

Cómo citar este artículo/Citation: Fuster García, F. (2014). "Yo, intelectual: Pío Baroja frente a las masas y la democracia". Arbor, 190 (765): a103. doi: http://dx.doi.org/10.3989/ arbor.2014.765n1012

Recibido: 03 julio 2013. Aceptado: 25 noviembre 2013.

RESUMEN: El objetivo de este artículo es trazar la evolución de la actitud de Pío Baroja como intelectual durante los últimos años del siglo XIX y las primeras décadas del siglo XX, justo el período durante el cual aparece y se consolida en España este nuevo sujeto social. Para ello, intento analizar el pensamiento del escritor vasco ante dos de los temas que más preocuparon a los intelectuales españoles y europeos en esta época: la relación del individuo con la masa y la postura del intelectual frente a la democracia.

PALABRASCLAVE: Pío Baroja; intelectual; España; masas; democracia.

\section{I, INTELLECTUAL: PÍO BAROJA ON THE MASSES AND DEMOCRACY}

Copyright: (C) 2014 CSIC. Este es un artículo de acceso abierto distribuido bajo los términos de la licencia Creative Commons Attribution-Non Commercial (by-nc) Spain 3.0.

ABSTRACT: This paper aims to chart how the Basque writer Pío Baroja's attitude as an intellectual evolved over the final years of the nineteenth and the early decades of the twentieth century, at a time when a new 'social subject' was emerging and becoming consolidated in Spain. It therefore analyses Baroja's thought in relation to two of the topics of greatest concern to Spanish and European intellectuals of the day: the relationship of the individual to the mass and intellectuals' attitude to democracy.

KEYWORDS: Pío Baroja; intellectual; Spain; masses; democracy. 
En Pío Baroja se da el caso que se ofrece en muchos pensadores y artistas contemporáneos. Merced a su agudo espíritu de análisis y a su desinterés intelectual, se encuentran, en un momento histórico y en un determinado medio social, con que ni pueden ser amparados -espiritualmente- ni aprobados por los elementos históricos, tradicionalistas, ni por los demócratas y revolucionarios.

Azorín, "Pío Baroja”, El Pueblo Vasco, 14-VI-1911

\section{LOS “INTELECTUALES” EN LA ESPAÑA DE FIN DE SIGLO}

La historiografía europea ha alcanzado cierto consenso a la hora de situar en la coyuntura del cambio de siglo la aparición de un nuevo sujeto social al que desde su nacimiento se ha designado con el nombre de "intelectuales". Por concretar más con las fechas, se suele convenir en que el surgimiento de esta figura se produce por primera vez en Francia, a raíz del llamado affaire Dreyfus y de la publicación del artículo "J'accuse", firmado por Émile Zola el 13 de enero de 1898 en el periódico L'Aurore. En España, el hito que se suele tomar como punto de partida para la aparición de este grupo es la campaña en favor de revisar los llamados "Procesos de Montjuic", emprendida desde distintos sectores de la prensa y la cultura e intensificada también en 1898, coincidiendo con las primeras alusiones al término "intelectual" en algún texto de Miguel de Unamuno y Ramiro de Maeztu. Por tanto, podemos decir que el uso de la palabra "intelectual" como sustantivo aparece en el vocabulario político español en torno a la fecha de 1898 y con ese mismo matiz de rebeldía y disconformidad con el que aparece en Francia, aplicado a aquel individuo que se separa del resto para emitir un juicio personal que suele ser crítico con el orden sociopolítico establecido.

Estos intelectuales que surgen en España durante el fin de siglo se diferencian del resto de la sociedad porque reclaman una función específica, sin asumir en ningún momento el liderazgo. Son - ha escrito Santos Juliá - como los liberales o los románticos, en el sentido de que "convierten la disidencia en un signo de distinción", protestan contra todo y se erigen en "árbitros morales de la nación"; sin embargo, y a diferencia de aquellos, "son incapaces de organizar un movimiento, proponer un programa de acción, señalar un objetivo: sienten una profunda aversión a lo concreto" (Juliá, 1998, 4). Efectivamente, una de las características que más se han señalado de este nuevo sujeto es la ausencia de unión en un grupo cuyos miembros podían coincidir en sus opiniones, sin necesidad de ponerlas al servicio de un principio rector; es más, se puede decir que los intelectuales compartieron unos mismos espacios de sociabilidad en tertulias y redacciones de periódicos pero, aun así, "rechazaron cualquier idea de organización y ni siquiera editaron revistas ni periódicos propios" (Juliá, 2001, 164). "Entre 1895 y 1905 - han dicho dos reconocidos hispanistas -, Unamuno, Baroja, Martínez Ruiz, Maeztu, etc., lanzaron muchas ideas pero, en definitiva, ¿qué valores comunes propusieron?" (Lissorgues y Salaün, 1991, 66) En este sentido, pues, parece bastante claro que aquello que compartía la generación de intelectuales que aparece en España durante el fin de siglo era solamente el deseo de renovarlo todo guiado por un ímpetu juvenil que, lógicamente, estaba destinado a evaporarse algún día.

Haciendo valer esta nueva condición, durante estos primeros años del siglo XX el escritor vasco Pío Baroja (1872-1956) empieza a combinar - y lo hará ya durante toda su vida - la creación de su obra literaria con la intervención en el debate público, manifestando sus opiniones en la prensa e interviniendo en una serie de actos cívicos (conferencias, charlas, mítines, etc.) que culminarán en un primer intento de acceder a la política municipal madrileña en 1909, como candidato del Partido Republicano Radical de Alejandro Lerroux. En las páginas siguientes quiero profundizar en la postura barojiana sobre dos de los temas que más preocuparon a los intelectuales españoles y europeos durante esta época: la relación del individuo con la masa y la actitud del intelectual frente a la democracia.

\section{BAROJA Y LAS MASAS}

Como han venido subrayando infinidad de autores, durante el período que abarca las tres primeras décadas del siglo XX el protagonismo de las masas adquiere una relevancia desconocida hasta ese momento en la historia de la Europa contemporánea. "Hay un hechoescribe Ortega y Gasset en 1929 - que, para bien o para 
mal, es el más importante en la vida pública europea de la hora presente. Este hecho es el advenimiento de las masas al pleno poderío social" (Ortega y Gasset, 2005, 375). El crecimiento y desarrollo demográfico de las grandes urbes europeas, propiciado por la llegada a la ciudad de oleadas migratorias procedentes del mundo rural, provoca que la población hasta entonces dispersa en núcleos de tamaño menor se acumule y se concentre en esas metrópolis tomadas por el fenómeno de las muchedumbres, como las llama Ortega:

La aglomeración, el lleno, no era antes frecuente. ¿Por qué lo es ahora? Los componentes de esas muchedumbres no han surgido de la nada. Aproximadamente el mismo número de personas existía hace quince años. Después de la guerra parecería natural que ese número fuese menor. Aquí topamos, sin embargo, con la primera nota importante. Los individuos que integran estas muchedumbres preexistían, pero no como muchedumbre. Repartidos por el mundo en pequeños grupos, o solitarios, llevaban una vida, por lo visto, divergente, disociada, distante. Cada cual individuo o pequeño grupo - ocupaba un sitio, tal vez el suyo, en el campo, en la aldea, en la villa, en el barrio de la gran ciudad.

Ahora, de pronto, aparecen bajo la especie de aglomeración, y nuestros ojos ven dondequiera muchedumbres (Ortega y Gasset, 2005, 376-377).

Es en este nuevo contexto donde se forja un pensamiento barojiano cuyo análisis parte necesariamente de una premisa: aquello que según nuestro autor hace incompatible la coexistencia de individuo y masa es el choque de dos sensibilidades que no encajan. Por eso, y pese a que en su obra hay una crítica severa a la incultura de la multitud y a su responsabilidad en esa ausencia de valores que caracteriza a la crisis finisecular, no se puede decir - como han pretendido algunos autores - que Baroja realiza una crítica a la sociedad española en abstracto. La sociedad, dice el escritor, no es mala por el hecho de ser sociedad; lo negativo para el individuo es vivir en una sociedad en la que no se siente a gusto:

Yo estoy convencido de que la vida no es buena ni mala; es como la naturaleza: necesaria. La misma sociedad no es tampoco ni buena ni mala. Es mala para el hombre que tiene una sensibilidad excesiva para su tiempo; es buena para el que se encuentra en armonía con el ambiente.

[...] El hombre debe tener la sensibilidad que necesita para su época y para su ambiente; si tiene menos, vivirá como un menor de edad; si tiene la necesaria, vivirá como un hombre adulto; si tiene más será un enfermo (Baroja, 1999a, 351) ${ }^{1}$.
Esta incompatibilidad de sensibilidades es justamente la que siente un Baroja que reaccionará adoptando esa actitud de individualismo radical que impregna su obra literaria y, en general, su cosmovisión del mundo. Desde su punto de vista, todas las instancias sociales que someten o encuadran al individuo son creaciones artificiales sin ninguna base sólida, sin ninguna autoridad moral que no sea la de una convención contranatural; una imposición coartadora de la personalidad y la originalidad del hombre:

La individual es la única realidad en la naturaleza y en la vida. La especie, el género, la raza, en el fondo no existen; son abstracciones, modos de designar, artificios de la ciencia, síntesis útiles, pero no absolutamente exactas. Con estos artificios discurrimos y comparamos; estos artificios constituyen una norma dentro de nosotros mismos, pero no tienen realidad exterior.

Sólo lo individual existe por sí y ante sí. Soy vivo; es lo único que puede afirmar el hombre.

Las agrupaciones o separaciones constituidas por la clasificación son como la cuadrícula que un dibujante pusiera delante de una figura para copiarla mejor. Las rayas de la cuadrícula dividirán las líneas del dibujo; pero las dividirán, no en la realidad, sino sólo en el campo visual del dibujante.

En lo humano, como en todo en la naturaleza, el individuo es lo único. Sólo lo individual existe en el campo de la vida y en el campo del espíritu (Baroja, 1998, 571).

Como ha escrito José-Carlos Mainer y ha coincidido en señalar toda la crítica, si algo define - además de su escepticismo - la mentalidad de Baroja es su acusado individualismo: "una intolerancia respecto a cualquier obstáculo que lo colectivo - Estado, Iglesia, Ley...- imponga a una "ley natural» que debe proteger a los rebeldes en su camino solitario" (Mainer, 1997, 31-32). Pero, a pesar de este individualismo, o quizá precisamente por ello, su curiosidad le lleva a interesarse vivamente por la relación entre el hombre y la masa, así como por el fenómeno de las multitudes y su comportamiento. Desde esta perspectiva, cabe decir que la visión barojiana de la masa no se nutre únicamente de su experiencia como intelectual, sino que sus juicios se ven enriquecidos también por la lectura que nuestro protagonista hará de reputados sociólogos y antropólogos europeos que durante estos primeros años del siglo XX elaboran las primeras teorías científicas sobre la psicología de las masas. Lo comprobamos en su ensayo "El espíritu de las masas", donde cita el nombre de algunos de estos autores muy en boga en la Europa del momento y presentes a través de sus títulos más representativos en la biblioteca personal del novelista: 
Hace ya treinta o cuarenta años se publicaron varios libros acerca de la psicología y del alma de las multitudes. Creo que la primera obra que trató de esta cuestión más o menos científicamente fue la del profesor italiano Sighele, y que a ésta siguieron las de Le Bon, Tarde y, por último, Freud (Baroja, 1999b, 1131).

Quizá uno de los aspectos de la sociedad en la que vive más detestados por Baroja es su tendencia a la uniformidad; la masa tiende por naturaleza hacia una homogeneización de los hombres que suprime su bien más preciado: la individualidad. Efectivamente, este abuso del poder de la masa a la hora de frenar y coartar la originalidad del hombre moderno es algo que el novelista no puede perdonar. En "Las ideas de ayer y de hoy" ironiza sobre la idea nietzscheana del "superhombre" y concluye que lo que predomina en la sociedad europea de principios del siglo XX es la mediocridad: "No hay signos de superhombría en el ambiente. Por el contrario, el hombre, por la presión de las masas, parece que tiende a hacerse más aborregado, menos individual, más social y, probablemente, más mediocre" (Baroja, 1999c, 1261).

Dice Azorín en La voluntad (1902) - expresando un principio compartido seguramente por nuestro autor - que "la originalidad, que es lo más alto de la vida, es lo que más difícilmente perdona el vulgo" (Azorín, 2008, 152). Quizá con esta afirmación en mente, en el prólogo a su novela César o nada Baroja insiste en la misma idea y amplía su teoría sobre el perjuicio que la masa provoca al individuo; para él, el ser humano es contradictorio por naturaleza y cada individuo posee unas características propias que le hacen diferente al resto. Por eso, lo ideal sería que los hombres pudieran vivir en sociedad, sin tener por ello que renunciar a su libertad individual; este equilibrio utópico entre lo general y lo particular, entre lo individual y lo colectivo, es lo que según Baroja, no se encuentra en una sociedad española en la que el individuo siempre sale perdiendo frente a la mayoría:

Sólo cuando la inarmonía individual deja de serlo, cuando pierde sus atributos de ser excepcional, cuando el molde se desgasta y se vulgariza y toma un carácter común, obtiene el aprecio de la mayoría.

"Es lógico; lo borroso ha de simpatizar con lo borroso; lo vulgar y lo genérico tienen que identificarse con lo genérico y lo vulgar"

Desde un punto de vista humano, lo perfecto en una sociedad sería que supiese defender los intereses generales, y, al mismo tiempo, comprender lo individual; que diera al individuo las ventajas del trabajo en común y la libertad más absoluta; que multiplicara su labor y le permitiera el aislamiento. Esto sería lo equitativo y lo bueno.
Nuestra sociedad no sabe hacer ninguna de estas dos cosas; defiende lo particular contra lo general, porque tiene como norma práctica la injusticia y el privilegio; no comprende lo individual, porque lo individual constituye la originalidad, y la originalidad es siempre un elemento perturbador y revolucionario (Baroja, 1998, 572).

Este análisis barojiano coincide con el de otros intelectuales y pensadores europeos que durante las primeras décadas del siglo XX Ilegan a las mismas conclusiones. Para Ortega y Gasset, uno de los efectos más nocivos de la masa es esta capacidad para eliminar todo lo que sobresale, lo que destaca o es diferente a la norma; sean del tipo que sean, las minorías selectas no tienen cabida en esta sociedad europea de las multitudes: "La masa arrolla todo lo diferente, egregio, individual, calificado y selecto. Quien no sea como todo el mundo, quien no piense como todo el mundo corre el riesgo de ser eliminado" (Ortega y Gasset, 2005, 380). Según el filósofo madrileño, el responsable de la degradación cultural de la sociedad europea tenía un nombre: el "hombre-masa". Si la masa impide la expresión de la individualidad es porque está integrada por individuos sin personalidad propia, por hombresmasa que forman ese todo amorfo y culturalmente pobre que es la masa. En la multitud no caben los extremos, solamente lo mediano, lo común. Por eso, dice Ortega, la masa es la unión de todo lo mediocre que hay en la sociedad:

Masa es "el hombre medio". De este modo se convierte lo que era meramente cantidad - la muchedumbre - en una determinación cualitativa: es la cualidad común, es lo mostrenco social, es el hombre en cuanto no se diferencia de otros hombres, sino que repite en sí un tipo genérico (Ortega y Gasset, 2005, 377).

En el caso de Baroja, esta crítica a la masa y a la sociedad de la época será doble, pues a la denuncia que hace el autor en calidad de intelectual se sumará la realizada a través de los muchos personajes autobiográficos que encontramos en sus novelas.

\section{BAROJA Y LA DEMOCRACIA}

La crítica de Baroja y otros intelectuales de su generación a las multitudes tiene su derivación lógica en el rechazo de todos ellos al modelo político con el que identifican a esas masas: la democracia. Más que una crítica a la democracia como ideal político, lo que abunda es una denuncia de la perversión de los valores democráticos que representa la entrada de las masas en la política por primera vez en la historia de España, a través de los partidos republicanos y socialistas que empiezan a tomar fuerza durante las 
primeras décadas del siglo XX como hipotética alternativa a los llamados "partidos dinásticos" de la Restauración. Como ha resumido Santos Juliá, "si la masa era el número y si el número decidía la formación de los Gobiernos, entonces los Gobiernos estaban por definición afectados del mismo daño que la masa" (Juliá, 1998, 5). No estamos, sin embargo, ante una especificidad española; este posicionamiento de los intelectuales frente a la democracia es generalizado para toda Europa. De hecho, son varios los pensadores europeos que durante esta época teorizan sobre el comportamiento político de las masas, publicando ensayos y monografías en los que argumentan sobre lo que supone para la sociedad europea la adopción de esa novedad que es el sufragio universal masculino.

Uno de estos sociólogos - citado por Baroja en ese texto al que ya he aludido anteriormente - es Gustave Le Bon, quien en su ensayo Psicología de las masas elabora una teoría que parte de reconocer que "el advenimiento de las clases populares a la vida política, su progresiva transformación en clases dirigentes, es una de las más destacadas características de nuestra época de transición" (Le Bon, 2005, 20). Le Bon estudia la sociedad europea finisecular y percibe un fenómeno que para él resulta incontestable: el ascenso de unas masas cuyas reivindicaciones las hacen cada vez más peligrosas, menos manejables. Dentro de la irracionalidad y la incultura que las caracteriza, las multitudes tienen, en cambio, una importante capacidad para la acción. De llegar al poder, cree Le Bon, las masas pueden provocar una involución de la sociedad occidental hasta un período pre-civilizatorio que él llama de "comunismo primitivo", de anarquía total o, lo que es peor, de tiranía de la masa:

En la actualidad, las reivindicaciones de las masas se hacen cada vez más definidas y tienden a destruir radicalmente la sociedad actual, para conducirla a aquel comunismo primitivo que fue el estado normal de todos los grupos humanos antes de la aurora de la civilización. Limitación de las horas de trabajo, expropiación de las minas, los ferrocarriles, las fábricas y el suelo; reparto equitativo de los productos, eliminación de las clases superiores en beneficio de las populares, etc. He aquí estas reivindicaciones.

Poco aptas para el razonamiento, las masas se muestran, por el contrario, muy hábiles para la acción. La organización actual convierte su fuerza en inmensa. Los dogmas que vemos nacer habrán adquirido muy pronto el poder de las viejas concepciones, es decir: la fuerza tiránica y soberana que queda fuera de discusión. El derecho divino de las masas sustituye al derecho divino de los reyes.
[...] El advenimiento de las masas marcará quizá una de las últimas etapas de las civilizaciones de Occidente, un retorno hacia aquellos períodos de confusa anarquía que preceden a la eclosión de las nuevas sociedades (Le Bon, 2005, 21-22).

Según este sociólogo, la actuación de las "masas electorales" se caracteriza por "una escasa aptitud de razonamiento, ausencia de espíritu crítico, irritabilidad, credulidad y simplismo". Si se otorga el voto a las masas, explica Le Bon, se corre el riesgo de dejar el poder para elegir en manos de personas sin criterio; las masas no tienen opinión propia y razonada, sino impuesta por individuos que no siempre tienen la mejor formación cultural como para ejercer de asesores políticos. Si el criterio para conceder el sufragio se basa en la cantidad de individuos y no en su calidad o formación intelectual, las consecuencias son fácilmente previsibles. "La grandeza de una civilización - afirma Le Bon - no puede depender, seguramente, del sufragio de elementos inferiores, que representan únicamente cantidad. Es también indudable que los sufragios de las masas son con frecuencia muy peligrosos" (Le Bon, 2005, 132-133). Pero en contra de lo que pudiera parecer por estas palabras, el autor no es partidario tampoco de un sufragio censitario más restringido; según su punto de vista, la solución no es esa. Para Le Bon, el sufragio restringido y limitado a los más inteligentes tendría el mismo problema que el sufragio universal. El problema no radica solamente en la inteligencia del votante, sino en el hecho de que en cualquier masa de cualquier tipo, las cualidades de los individuos tienden a igualarse a la baja, lo cual siempre es un hecho negativo:

¿Hemos de suponer entonces que un sufragio restringido - restringido a los capaces, si se quiere - mejoraría el voto de las masas? No puedo admitirlo ni por un instante y ello por los motivos antes señalados y relativos a la inferioridad mental de todas las colectividades, sea cual fuere su composición. En masa, y lo repito, los hombres se igualan siempre y, por lo que respecta a cuestiones generales, el sufragio de cuarenta académicos no es mejor que el de cuarenta aguadores. [...] Ante problemas sociales, llenos de múltiples incógnitas y dominados por la lógica mística o la lógica afectiva, todas las ignorancias se igualan (Le Bon, 2005, 134).

Otro autor leído y citado por Baroja que también tercia en este debate sobre las masas y su lugar en la sociedad europea de principios del siglo XX es el sociólogo y criminólogo francés Gabriel Tarde, que en 1901 publica la que quizá sea su obra más conocida e influyente: La opinión y la multitud. En esta mono- 
grafía en la que se estudia la evolución de las masas europeas hasta su conversión en lo que Tarde llama "público", el autor dedica unas líneas a exponer su argumento sobre lo que podría suponer la entrada de las multitudes en la política. Para este sociólogo, el mayor peligro para las democracias europeas que nacen en el cambio de siglo es su posible obsesión por intentar controlar a las masas, ya que, según él, esa es una tarea que corresponde a los intelectuales, que son los encargados de dar ejemplo a la sociedad y de hacerlo tomándose mucho cuidado en su contacto con las masas, cuyo nivel cultural deben intentar elevar. Para evitar la perversión de la democracia, los intelectuales deben guiar a las masas, pero siempre resistiendo y manteniendo su situación privilegiada, sin rebajarse nunca a su nivel:

El peligro de las nueva democracias está en la dificultad creciente para los hombres de pensamiento de escapara a la obsesión y a la agitación fascinadora. Es muy peligroso descender en una campana de inmersión en un mar muy agitado. Las individualidades dirigentes, que nuestras sociedades contemporáneas ponen de relieve, son cada vez más los escritores que viven en continuo contacto con ellas; y la poderosa influencia que ejercen, preferible seguramente a la crueldad de las multitudes acéfalas, constituye ya un desmentido infligido a la teoría de las masas creadoras. [...] Lo que preservará de la destrucción y del nivelamiento democrático a las cimas intelectuales y artísticas de la humanidad no será, yo lo creo, el reconocimiento por el bien que el mundo les debe, la justa valoración del coste de sus descubrimientos. ¿Qué será, pues...? Yo quiero creer que será su fuerza de resistencia (Tarde, 1986, 77).

Sin entrar a valorar sus aventuras políticas, más relacionadas con un posible y legítimo deseo de notoriedad pública que con una adhesión decidida a una ideología concreta, lo cierto es que Baroja no tuvo jamás una postura política definida. Lo único que sí se detecta en todas las opiniones vertidas por el novelista vasco a lo largo de su vida es un deseo de romper con la tradición y de acabar con los privilegios del pasado e, igualmente, un temor a que esta ruptura signifique que lo nuevo sea igual o peor que lo viejo; que lo que nazca sea una democracia controlada por la masa a través del sufragio:

Todo lo que tiene el liberalismo de destructor del pasado me sugestiona: la lucha contra los prejuicios religiosos y nobiliarios, la expropiación de las comunidades, los impuestos contra la herencia, todo lo que sea pulverizar la sociedad pasada, me produce una gran alegría; en cambio, lo que el liberalismo tiene de constructor, el sufragio universal, la democracia, el parlamentarismo, me parece ridículo y sin eficacia (Baroja, 1999a, 424).

Más que su oposición el régimen de la Restauración, que también existe, lo que demuestra la crítica barojiana a la democracia es la animadversión que siente nuestro autor hacia las multitudes y hacia el abuso de poder que en ellas intuye. Es su individualismo y la desconfianza que siente hacia lo que las masas pueden hacer si acceden a la política lo que le hace recelar de la democracia:

Actualmente parece que el formar masas es el ideal de los partidos políticos. ¿Lo será siempre? No lo sabemos. Los individualistas desearíamos que este ideal fuese transitorio y que se volviera a pensar en los eternos valores personales; pero quizá ya es tarde.

La masa, que cuando protesta es rencorosa y de un sentimentalismo ridículo y pueril, cuando manda es despótica y sanguinaria. Su moral es muy pobre. ¿Se mata? No se podía hacer otra cosa. Antes la vida humana valía mucho; ahora comienza a no valer nada. La política de masas produce: o la dictadura socialista, o la fascista.

Con una o con otra, el gobierno es tiránico y pedantesco, dirigido por gente mediocre y endiosada, apoyado por burócratas, policías y guardias de todas clases (Baroja, 1999b, 1315).

Cuando en sus memorias repase su vida y los diferentes juicios que sobre su postura política se han hecho, Baroja insistirá en que nunca fue afiliado de un partido político ni defensor acérrimo de ninguna ideología. Lo que sí admite es haber mantenido siempre una concepción negativa del comunismo y del socialismo como modelos políticos más favorables a la entrada de las masas en política. Por eso, este rechazo a la democracia como gobierno del pueblo, de la masa social inculta, es la única constante ideológica en la trayectoria vital barojiana:

Siempre he tenido recelo y poco amor por la democracia y el comunismo. Ya en todas las manifestaciones democráticas de hace años me parecía ver un peligro. Todos los públicos grandes me han producido desconfianza y, a veces, terror. No creo que una masa social pueda ir a nada bueno. Todo en ella serán apetitos un poco brutales, nunca pensamientos nobles ni juicios claros.

Como digo, siempre he tenido recelo por el avance de las teorías democráticas y socialistas (Baroja, 1997, 297).

En varios de sus escritos, Baroja se refiere a la democracia como una "broma etimológica", en el sentido de que lo que para otros es el gobierno del pueblo, para él es un dominio de la masa que, además, viene 
acompañado de una "mixtificación de oradores", en referencia a la inepcia de los políticos españoles y a su ridícula propensión a la oratoria pomposa y vacía de contenido. Además, añade el escritor, uno de los peores aspectos del debate sobre la democracia es que la mayoría de la gente habla de un concepto cuyo significado desconoce totalmente. Para Baroja, la gente confunde la solidaridad o el legítimo y humano deseo de la bondad de los unos para con los otros, con un sistema político en el que, bajo la apariencia de una mayor justicia, se producen los atropellos más insospechados. Como leemos en un temprano artículo publicado ya en 1899 con el elocuente título de "Contra la democracia", por no gustarle, de la democracia no le gustaba ni el nombre:

¡Oh la democracia! Es la palabra más insulsa que se ha inventado. Es como la pirueta del cómico de mi pueblo; la mayoría no sabemos lo que es la democracia ni lo que significa, $y$, sin embargo, nos sugestiona y nos hace efecto.

[...] Hay algo que se llama democracia; una especie de benevolencia de unos por otros, que es como la expresión del estado actual de la humanidad, y ésa no se puede denigrar; esa democracia es un resultado del progreso.

La otra democracia, de la que tengo el honor de hablar mal, es la política, la que tiende al dominio de la masa, y que es un absolutismo del número, como el socialismo es un absolutismo del estómago.

He leído, como todo el mundo, algo acerca de la democracia, pero no tengo una idea clara de lo que es; etimológicamente, significa "gobierno del pueblo", pero yo creo - quizá me engañe - que el pueblo no ha mandado nunca ni en los tiempos más revolucionarios y que tampoco mandará en el porvenir.

¿Qué tienen representantes o delegados que mandan por él? Riámonos de eso. Es la farsa más estupenda que se ha inventado (Baroja, 1999d, 128-129).

Aunque ya he dicho que la censura barojiana a la política y a los políticos es generalizada y no entiende de partidos ni de ideologías, si es verdad que hay ciertas ideas a las que el autor les tiene una especial inquina. Quizá el pensamiento que mayor rechazo le genere a Baroja sea el socialismo. Parte de la crítica ha querido ver en esta oposición una razón autobiográfica, en el sentido de relacionar esta animadversión con la mala experiencia que tuvo el por entonces incipiente escritor cuando estuvo durante varios años al frente del negocio de la panadería de su tía-abuela, Juana Nessi, en Madrid. Como es sabido, esta breve etapa como empresario y miembro de la pequeña burguesía empezó relativamente bien, pero terminó francamente mal, con el abandono del empeño por parte de un Baroja que en sus memorias atribuye una importante responsabilidad en el fracaso de esta aventura empresarial a los obreros que trabajaban en la tahona que él administraba y que - siempre según su versión - le hicieron la vida imposible con sus quejas. Ahí fue cuando nuestro autor sufrió en carne propia el enfrentamiento entre esa clase obrera asalariada que por primera vez empezaba a organizarse en demanda de derechos y mejoras laborales, y la clase empresarial o patronal (aunque en su caso se tratara de un pequeño negocio como era una panadería) en la que circunstancialmente se encontraba él. Aunque no se puede establecer una relación de causa-efecto infalible, si es posible, y así se aprecia en varios de sus escritos, que esta experiencia marcara la visión negativa que el escritor tuvo durante su vida no ya de la clase obrera, sino de sus líderes políticos y sindicales. Esta especie de rencor hacia los dirigentes obreros por aquel episodio autobiográfico sí que contribuyó, junto con otros factores, a esta aversión a la doctrina socialista que el novelista vasco nunca ocultó. Valga como muestra esta reflexión en el artículo "Burguesía socialista", publicado cuando todavía no había abandonado el negocio de la panadería:

Dada la adoración por el número y por la masa que hoy se siente, yo me figuró que el porvenir será socialista; pero, a pesar de eso, siento una antipatía profunda por esa doctrina y por ese partido, que trae la glorificación de la manada, el apabullamiento del individuo por lo demás.

A pesar de lo que dicen los periódicos representantes del capitalismo, a nosotros, médicos, abogados, ingenieros, pequeños industriales; a los que queremos trabajar para vivir, no nos asustan más los anarquistas que los socialistas. Éstos nos quieren convertir en obreros; aquéllos sueñan con darnos a cada uno de los hombres nuestra casita, nuestra tierrecilla y un trabajo cualquiera para entretenernos.

[...] Si llegara esa dulce era de la vida en rebaño, por mi parte, antes de ocupar el número ochenta o noventa mil que me tocara en el gran pesebre socialista, preferiría emigrar, refugiarme en otro país más atrasado y menos socialista, aunque no tuviera allí más derecho que el derecho al santo revólver (Baroja, 1999e, 118).

Pero esta crítica al socialismo no tiene únicamente como origen este episodio autobiográfico; de hecho, podemos decir que esa experiencia pequeño-burguesa de Baroja le sirvió para afirmarse en sus convicciones sobre lo nocivo que resulta para la personalidad 
del individuo este comportamiento colectivo en el que el rebaño - término nietzscheano muy del gusto de nuestro autor - sigue incondicionalmente a un pastor, a un líder supuestamente aventajado. En el prólogo a César o nada, que ya he citado, da una definición de lo que, según él, sería un ideal de democracia basado no en la igualdad obligatoria de los individuos, sino en la igualdad de oportunidades y en el desarrollo libre de las capacidades de cada cual, en libre convivencia y competencia con el otro. Tristemente, piensa el novelista, el miedo de la masa a esa originalidad del hombre que se sale de lo establecido es lo que impide que este modelo barojiano de democracia sea factible:

\begin{abstract}
Una democracia refinada sería la que, prescindiendo de los azares del nacimiento, igualara en lo posible los medios de ganar, de aprender y hasta de vivir, y dejara en libertad las inteligencias, las voluntades y las conciencias, para que se destacaran unas sobre otras. La democracia moderna, por el contrario, tiende a aplanar los espíritus, e impedir el predominio de las capacidades, esfumándolo todo en un ambiente de vulgaridad. En cambio, ayuda a destacarse unos intereses sobre otros.
\end{abstract}

Gran parte de la antipatía colectiva por lo individual procede del miedo. Sobre todo en nuestros países del sur. Las individualidades fuertes han sido inquietas y tumultuosas, las manadas de arriba, como las de abajo, no quieren que florezcan en nuestras tierras las semillas de los César o de los Bonaparte. Esas manadas anhelan la nivelación espiritual; que no haya más distinción entre un hombre y otro que un botón de color en la solapa o un título en la tarjeta. Tal es la aspiración de los tipos verdaderamente sociales; las demás distinciones, el valor, la energía, la bondad, para los demócratas laminadores son verdaderas impertinencias de la naturaleza (Baroja, 1998, 572-573).

Es cierto que analizando en mayor profundidad la obra barojiana se percibe algo que ya apuntó Azorín y que también he intentado argumentar en estas páginas; me refiero al hecho de que, más que un crítico de la democracia en abstracto, como un sistema político que no es apto para ninguna sociedad, lo que el Baroja intelectual denuncia es la forma perversa de la democracia que desde su punto de vista se da en la España de su tiempo. Al margen de la ya conocida corrupción electoral del sistema canovista, lo que el novelista vasco aborrece de la política española es el haber dado entrada a las muchedumbres, a la masa inculta. Y le molesta esto especialmente porque, como se desprende de lo dicho por Azorín, muchedumbre y aristocracia no son para Baroja clases sociales, sino una especie de "clases culturales", esto es, de cualidades del ánimo y el intelecto de cada individuo aislado, que nada tienen que ver con su estrato social ni con su poder económico. Así lo explica el novelista alicantino al referirse a la ideología de su amigo y compañero en esa primera generación de intelectuales españoles:

Hay muchas páginas en los últimos libros de Baroja - Juventud, egolatría; Las horas solitarias - que nos harían pensar en un impugnador de la democracia. Guardémonos de observación tan imparcial; es preciso considerar la obra completa de Baroja, y, sobre todo, el espíritu que informa esa obra. ¿Qué es la muchedumbre? ¿Qué es la aristocracia? Muchedumbreen su sentido despectivo - es lo mismo un ciudadano que ocupa una eminentísima posición que otro que la ocupa humilde; muchedumbre puede ser - por sus sentimientos vulgares, por su incultura - el duque, el ex ministro, el gran propietario el excelentísimo don Fulano, el ilustrísimo don Mengano. Y aristocracia puede ser el obrero o el labriego inteligentes, cultos, conscientes de su misión y de su fuerza. Los antiguos conceptos de clases deben ser rotos para nosotros (Azorín, 2012, 150).

Y es que, como ya he apuntado, la mala opinión que Baroja tiene de la masa y de la democracia fue compartida por la mayoría de integrantes de aquella primera generación de intelectuales españoles. Lo que sucede en el caso de nuestro autor y lo diferencia del resto es que fue uno de los que con más vehemencia defendió esta postura y - eso sí - el único que la conservó de forma invariable durante toda su vida. Si otros intelectuales abandonaron pronto esa misión de crítica social y algunos se acercaron tanto a la política que acabaron formando parte de ella y ejerciendo algún cargo, Baroja fue el que se mantuvo más fiel a sus convicciones y a esa labor de crítica de la sociedad y de los vicios del sistema político vigente, ya fuera este el de la Restauración, la Dictadura de Primo de Rivera o la Segunda República. Como dice José-Carlos Mainer, "nuestro escritor fue, de todos los de su tiempo, quien menos modificó el paradigma inicial: liberal, por odio a toda sumisión, pero nada democrático"; en eso, explica Mainer, Baroja se comportó igual que los europeos de su generación, "incapaces de cohonestar el igualitarismo electoral y la eficacia de lo público, las necesidades del progreso y las inercias de la incultura colectiva" (Mainer, 1998, 89).

Efectivamente, Baroja se mantuvo fiel durante toda su vida a una postura entre liberal y anarquista, si se puede decir así, definida por lo único que siempre tuvo claro: el rechazo a la masa y a todo lo que representa el sometimiento del individuo a una instancia superior del tipo que sea. Así lo resume él mismo en Juventud, egolatría: "Yo he sido siempre un liberal, in- 
dividualista y anarquista. Primero, enemigo de la Iglesia; después, del Estado; mientras estos dos grandes poderes estén en lucha, partidario del Estado contra la Iglesia; el día que el Estado prepondere, enemigo del Estado" (Baroja, 1999a, 424). Tal vez por eso, por no comprometerse con nada que no fuesen sus pro- pios e irrenunciable principios (eso que Ortega y Gasset llamó su "fondo insobornable"), a Baroja le pasó y le sigue pasando lo que, según Antoine Compagnon, les sucede a los pensadores antimodernos: "la derecha piensa que son de izquierdas, y la izquierda piensa que son de derechas" (Compagnon, 2007, 249).

\section{NOTAS}

1 A partir de este momento, siempre que cite a Pío Baroja lo haré siguiendo la edición de sus Obras Completas (OC) dirigida por José-Carlos Mainer y publicada en dieciséis volúmenes por el Círculo de Lectores y la editorial Galaxia Gutenberg entre 1997 y 1999.

\section{BIBLIOGRAFÍA}

Azorín (2008 [1902]). La voluntad. Edición de María Martínez del Portal, Madrid: Cátedra.

Azorín (2012 [1919]). "El genio y la masa”. En Ante Baroja (1900-1960): edición crítica, revisada y ampliada. Edición y estudio introductorio de Francisco Fuster García, Alicante: Publicaciones de la Universidad de Alicante.

Baroja, Pío (1997 [1944]). Desde la última vuelta del camino. En OC, Vol. I, Barcelona: Galaxia Gutenberg-Círculo de Lectores.

Baroja, Pío (1998 [1910]). César o nada. En OC, Vol. VIII, Barcelona: Galaxia Gutenberg-Círculo de Lectores.

Baroja, Pío (1999 [1917]). Juventud, egolatría. En OC, Vol. XIII, Barcelona: Galaxia Gutenberg-Círculo de Lectores.

Baroja, Pío (1999 [1933]). "El espíritu de las masas". En Rapsodias, OC, Vol. XIV, Barcelona: Galaxia Gutenberg-Círculo de Lectores.
Baroja, Pío (1999 [1933]). "Las ideas de ayer y de hoy". En Rapsodias, OC, Vol. XIV, Barcelona: Galaxia Gutenberg-Círculo de Lectores.

Baroja, Pío (1999 [1899]). "Democracia y mala educación". En El tablado de Arlequín, OC, Vol. XIII, Barcelona: Galaxia Gutenberg-Círculo de Lectores.

Baroja, Pío (1999 [1902]). "Burguesía socialista". En El tablado de Arlequín, OC, Vol. XIII, Barcelona: Galaxia GutenbergCírculo de Lectores.

Compagnon, Antoine (2007 [2005]). Los antimodernos. Traducción de Manuel Arranz, Barcelona: Acantilado.

Juliá, Santos (1998). "La aparición de «los intelectuales» en España". Claves de Razón Práctica, no 86, pp. 2-10.

Juliá, Santos (2001). "Algunas maneras de ser intelectual en la política". En Morales Moya, Antonio (coord.), Las claves de la España del siglo XX: la cultura. Madrid: Sociedad Estatal España Nuevo Milenio, pp. 153-180.
Le Bon, Gustave (2005 [1895]), Psicología de las masas. Traducción de Alfredo Guerra y prólogo de Florencio Jiménez Burillo. Madrid: Morata.

Lissorgues, Yvan y Salaün, Serge (1991). "Crisis del realismo". En Serrano, Carlos y Salaün, Serge (eds.), 1900 en España. Madrid: Espasa-Calpe, pp. 161-191.

Mainer, José-Carlos (1997). "La sustancia barojiana”. En Baroja, Pío, OC, Vol. I, Barcelona: Galaxia Gutenberg-Círculo de Lectores.

Mainer, José-Carlos (1998), “Pío Baroja, fin de siglo". En Mainer, José-Carlos y Gracia, Jordi (eds.). En el 98: los nuevos escritores. Madrid: Visor.

Ortega y Gasset, José (2005 [1929]). La rebelión de las masas. En OC, Vol. IV. Madrid: Taurus - Fundación Ortega y Gasset.

Tarde, Gabriel (1986 [1901]), La opinión y la multitud. Prólogo y traducción de Eloy Terrón. Madrid: Morata. 